\title{
Hasta luego danzante etéreo Ante la partida de Carlos René García Escobar Guatemala: 23.12.1948-7.12.2018
}

\author{
Until then ethereal dancer \\ Before the departure of Carlos René García Escobar \\ Guatemala: 12. 23.1948-12.7.2018 \\ Alfonso Arrivillaga-Cortés
}

Dirección General de Investigación, Universidad de San Carlos de Guatemala

*Autor al que se dirige correspondencia: laruduna@gmail.com

Como en todo lo que hiciste, hasta en tu partida fuiste especial. Varios sustos previos, para finalmente ese 7 de diciembre, en plena víspera de la Virgen de Concepción, entre los preparativos de las tradiciones que tanto estudiaste, las luminarias te recogieron. Tres días después, el domingo 9, con el cortejo de tus amigos danzantes, entre moros y cristianos, toritos, vaqueros, por su puesto toques de pito y tamborón, y la marimba regidora, todos al unísono te llevaron de la mano para iniciar tu camino al más allá. En definitiva fue inesperado, tenías tantos planes, varios proyectos de nuevos libros, continuabas en la investigación, ahora para el Instituto Panamericano de Geografía e Historia. Para Aportes para la Descentralización de la Cultura (Adesca), también dedicaste tu sabiduría y esfuerzo luego de tu jubilación de nuestra alma mater, esta casa de estudios a la que le dedicaste más de treinta años. Dado que continuamos compartiendo un espacio en la Comisión de Investigación del Arte en Guatemala, la CIAG, debo agregar ahí que además de tu liderazgo, generabas siempre desde la mirada crítica tu empeño por una mejor patria. Sabrás bien de la admiración y respeto que te tenía, ya te lo había externado en vida varias veces a lo largo de nuestro recorrido como mi maestro, hermano mayor y amigo.

Quizá por ello la vida me dio el honor de realizar en dos ocasiones sendos encomios de tu persona. En el Congreso Centroamericano de Antropología del 2008 y las jornadas de Investigación del Arte de la CIAG el año que recién dejamos 2018. Ambos eventos dedicados a tu persona y trayectoria y de los que nacieron dos sones dedicados a tu persona: Son-vos, y, Jazz-son.
Luego de esta rabia que da tu partida, vendrán justas y mejores reflexiones, ahora era imponderable no avanzar en este homenaje para vos cultor de lo intangible, y en este número especial de la revista Ciencias Sociales y Humanidades, del que fuiste como en otros nuestro gran colaborador.

Carlos René García Escobar es un antropólogo egresado de la Escuela de Historia, en donde fue catedrático una vez egresó. Asimismo se dedicó a la investigación desde el Centro de Estudios Folklóricos (Cefol), donde fundó y dirigió a lo largo de treinta años el Área de Etnocoreología, en la cual produjo varios libros y artículos producto de sus investigaciones. Sus exploraciones estuvieron marcadas por una inmersión total del fenómeno danzario, llegando a ser un danzante importante y conocedor de la temática. A partir de su libro, Detrás de la Máscara (1989), mostró ya la ruta que seguiría este estudioso, poco antes como señalado este recorrido nos trajo; Trajes, danzas y morerías (1987), y luego de El Baile del Español (1990), y de un buen grueso de artículos nos lego su Atlas Danzario de Guatemala (1996, 2009), todos literatura académica central para la historia del arte y la cultura en Guatemala y Mesoamérica.

Además de su distinguida carrera como antropólogo, García Escobar, por cierto especializado en Panamá en donde fue becario de la Organización de Estados Americanos, (OEA), consolidó una importante carrera como escritor. Cuando estaba terminando su tesis, nuestro maestro en la Escuela de Historia de la Usac, Azzo Guidinelli le decía que no era necesario 
este esfuerzo; que su primera novela la Llama del Retorno, era además una interesante tesis de antropología, como en efecto estuvo marcada la obra de este escritor. Luego como era de esperar llegaron otras: Ofensiva Final, El Valle de la Culebra y Avatar, un esfuerzo que luego es re-editado en su conjunto como Novelario (2018). Sus títulos y campos de abordaje son mayores, su labor como periodista y como editor entre estas. Por años sostuvo el suplemento Teluria Literaria en el Diario la Hora, escribió sobre el grupo Vértebra, y siempre fue muy cercano también a los ar- tistas plásticos, impulsor de nuevos escritores, de buen caer, amigo, comprometido con la lucha, revolucionario, consecuente, entre otros calificativos.

A los pocos meses de su partida, varios conversatorios se ha organizados, entre estos el impulsado por sus amigos del Centro Pen, ente al que apoyo para su consolidación en el país. Queda a futuro inmediato, destacar de una manera mas sistemática su legado y aportes metodológicos.

Un fuerte abrazo y buen viaje, ahora danzante etéreo...

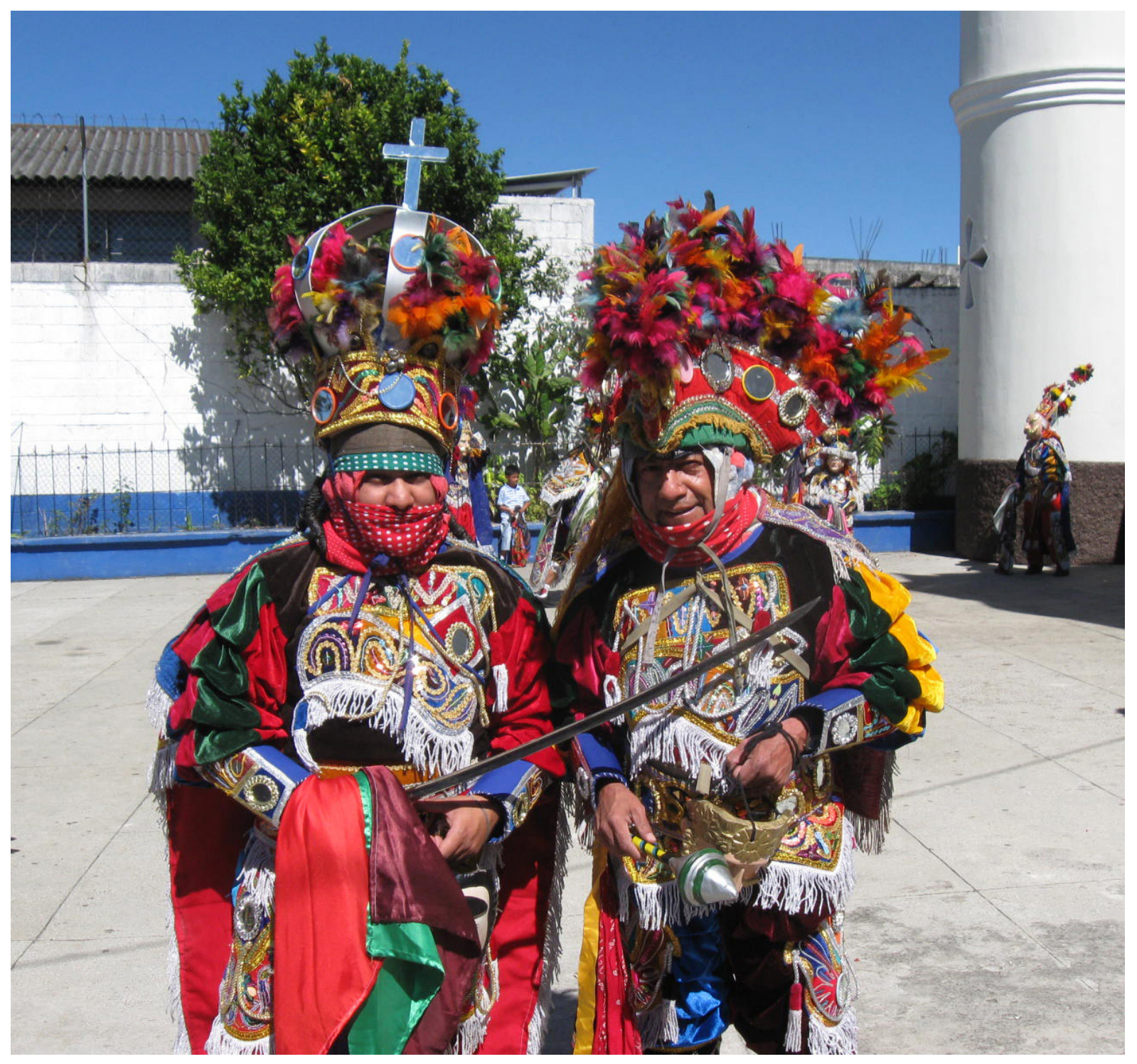

Figura 1. Carlos René García Escobar vestido de vaquero sin máscara para la danza de los Siete Toritos, Aldea lo de Bran Mixco.(Fotografía: Carlos Ariel García Salazar ) 


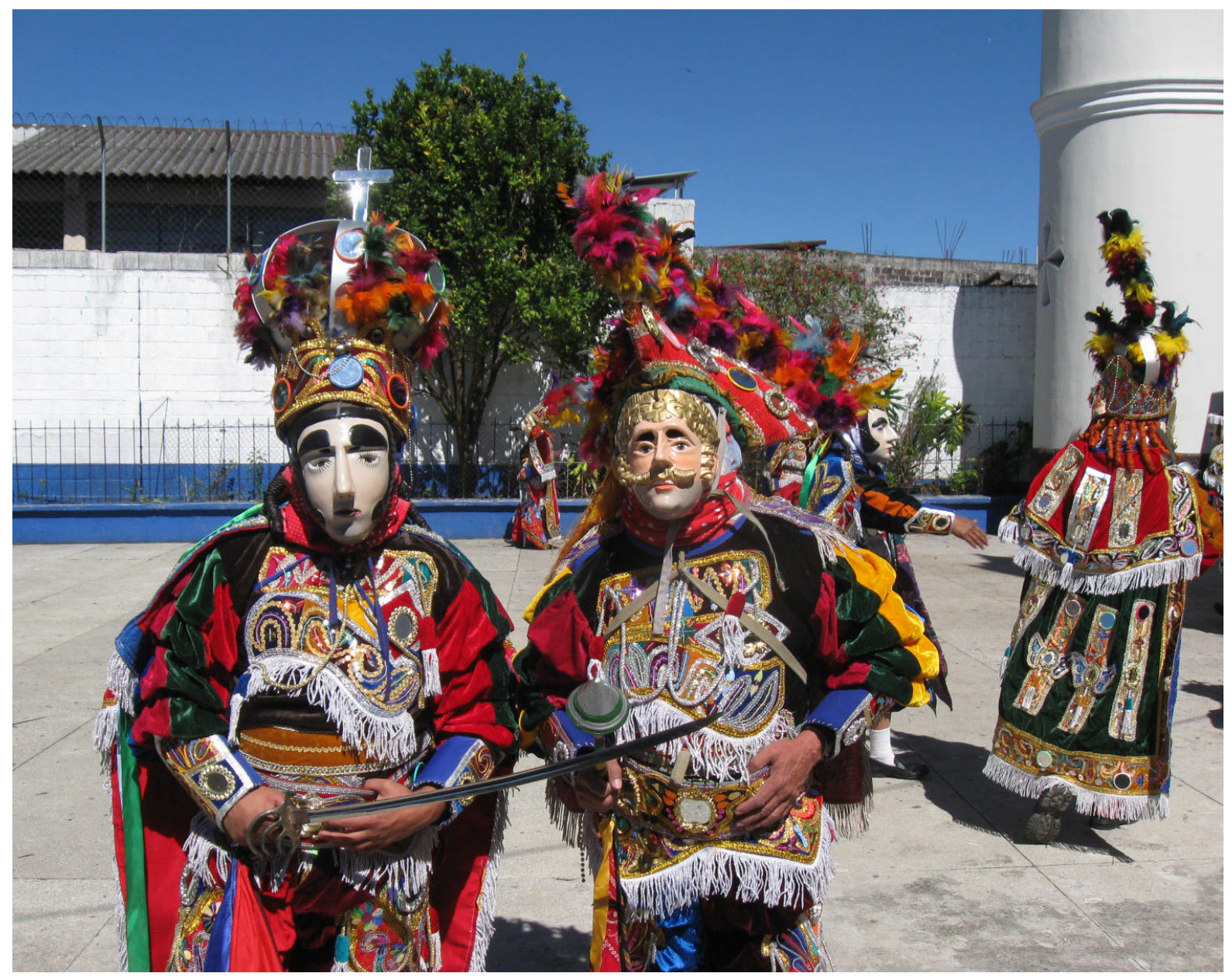

Figura 2. Carlos René García Escobar vestido de vaquero con máscara para la danza de los Siete Toritos, Aldea lo de Bran Mixco.(Fotografía: Carlos Ariel García Salazar ) 